\title{
Looking forward to the East African Countries' Collaboration in Nursing and Midwifery Education, Practice and Legislation
}

\author{
Sebalda Leshabari ${ }^{1^{*}}$, Rose ChaloNabirye ${ }^{2}$, Donatilla Mukamana ${ }^{3}$, Judy Mill ${ }^{3}$ \\ ${ }^{1}$ Mubimbili University of Health and Allied Sciences, School of Nursing, Dar es Salaam, Tanzania \\ ${ }^{2}$ Makerere University, College of Health Sciences, Department of Nursing, Kampala, Uganda \\ ${ }^{3}$ University of Rwanda, College of Medicine and Health Sciences, School of Nursing and Midwifery, Kigali, Rwanda
}

\begin{abstract}
In 2014, the East African Community (EAC) partner states began to explore the possibility of harmonizing nursing and midwifery education, practice and legislation. A study to examine harmonization was commissioned and variations in nursing and midwifery education, practice and legislation were discussed among academic institutions in the region. These variations included: admission requirements; duration of training for the same academic programs; and outcome competencies of the graduates. These differences have hindered the labor mobility of nurses and midwives in the region and provide solid rationale for the reciprocal recognition of nurses and midwives in the EAC through the harmonization process. The Global innovations in Nursing and Midwifery Education, Research and Practice Conference held in January 2015 in Kigali Rwanda provided an opportunity for University Deans in the East African region to dialogue and examine possible areas of collaboration between academic institutions in the East African (EA) region using a sustainable partnership model for the advancement of nursing and midwifery education, research and practice. This paper discusses the possibilities to achieve an East African collaboration through adapting Collaborative Change: An Interdependent Model of Nursing Education and experiences from the Norads Program for Master's Studies (NOMA) Regional Masters in Nursing initiative.
\end{abstract}

Key words: nursing, midwifery, education, research, clinical practice, partnership, East Africa

\section{Introduction, Background and Historical Context}

In East Africa and globally, nurses and midwives form the backbone of health service delivery. The quality of care, and thus patient satisfaction with care, is often dependent on the competencies of nurses and midwives working at all levels of care in public and private institutions and single-discipline clinics (WHA, 2011).

Although the practice of nursing is as old as the human race, formal nursing and midwifery education in East Africa did not start until the $19^{\text {th }}$ Century and most of the EA partner states inherited the colonial system of education that did not emphasize competencies. Nurses and midwives were therefore trained to assist physicians and practice was not based on research evidence (Klopper \& Uys, 2013).. Current developments in nursing and midwifery are taking place in the context of growing demands for accessible and affordable high-quality care and the need for improved access to care and universal coverage (Kinnaman \& Bleich, 2004; Rolince et al., 2001). Realizing the critical role of nurses and midwives in reducing mortality, morbidity, disability, and promoting healthy lifestyles, the World Health Assembly (WHA) resolution 62.12 directed countries to strengthen nursing and midwifery professions in order to maximize their contribution to the health of the population (WHA, 2009). In the same resolution, countries were urged to strengthen nursing and midwifery professions in areas of management, education, legislation, policy planning, regulation and practice, in order to meet the needs of the populations they served (WHA, 2006).

The call to educate and retain adequate numbers of health workers with appropriate skill mixes was reiterated in resolutions WHA62.12 (3) and

*Corresponding author: seolesh@yahoo.com 
WHA64.7 (WHA, 2011). However, the expanding complexities in health-care provision, the increasing number of health professionals at different levels, and the need to assure more equitable access to health care, demanded action on commitments to scale up the development and implementation of high-quality nursing and midwifery education, research and practice (WHO, 2010).

In the 21 st Century, health challenges have become complex with respect to diverse socio, cultural and socio-economic changes and increased patient care needs and environments (Kinnaman \& Bleich, 2004; Rolince et al., 2001). This dramatic shift requires advanced competencies in leadership, health policy and systems, and the education of well-prepared nursing and midwives to meet these competencies.

\section{Nursing and Midwifery Development in East Africa}

Recent advances in nursing and midwifery education in the East African Community have resulted in higher levels of specialization and education for nurses at the Masters and PhD levels. However, East African community partner states still have a high percentage (about 90\%) of nurses and midwives educated at the certificate and diploma levels only (verbal communication with the Registrars from the five EAC states Nursing and Midwifery regulatory bodies). This percentage is below levels of other African Regions. Equally important to note is that currently, the admission requirements, duration of training, and outcome competencies of graduates for the same academic programs vary among academic institutions in the EAC states. This causes decreased labor mobility among nurses and midwives in the EAC partner states and emphasizes the need for harmonization and mutual recognition of programs.

\section{Legal and Institutional Framework}

The harmonization of nursing and midwifery education and practice in the East African Community (EAC) partner states is in line with the relevant provisions of the Treaty on the establishment of the East African Community (Chapter 21, Article 118) (EAC, 2007). Under this provision, the East African Community partner states are required to harmonize and strengthen regional and national policies, laws, regulations, human resources, and institutional and infrastructure capacity in order to achieve quality health within the EAC, including the development of specialized health training, health research, preventive, curative and rehabilitative health services, and the provision of high quality nursing and midwifery services [Chapter 17 (Art. 104 (3)) and Chapter 21 (Article 118) of the EAC (EAC, 2007).

The need for harmonization was affirmed by the $3^{\text {rd }}$ and $4^{\text {th }}$ Ordinary Meetings of the EAC Sectoral Council of Ministers of Health and also the $15^{\text {th }}$ and the $18^{\text {th }}$ Ordinary Meetings of the EAC Council of Ministers that considered the progress of regional cooperation and integration in the health sector. Representatives from the member states established the East African Community Health Professions Authority (EACHPA) and also National Health Professions Authorities (NHPAs) in each Country (EAC, 2014).

\section{Aims of Harmonization}

Under the common market protocol and mutual recognition, the harmonization process is aimed at strengthening and harmonizing EAC regional and national policies, laws and regulations to promote free movement of health workers and goods, increase trade and provision of quality health services, and harmonize training and practice of various health professions in the region (EAC, 2014). This process is to be done in accordance with the relevant provisions of the EAC Common Market Protocol and the Treaty on the Establishment of the East African Community.

\section{Methods}

\section{The Process of Harmonization}

The East African Community Secretariat commissioned a consultancy study to "develop regional harmonization of nursing and midwifery education and practice in the East African Community Partner States" in collaboration with the Aga Khan Development Network (AKDN).The consultancy began with a regional consultative meeting with registrars of Nursing and Midwifery councils from EAC member states to review the status of nursing education, regulation and practice. Together with the registrars, activities for the national consultative meetings were planned.

National consultative meetings in each EAC 
member state were held to bring together nurses and midwives from different areas of nursing and midwifery practice, education and administration, and stakeholders from government and private institutions, to give their views on the harmonization of nursing and midwifery in EAC. At the end of the study, a regional workshop for all stakeholders including Chief Nursing Officers, Registrars of Nursing and Midwifery Councils, representatives from Ministries of Health, representatives from Nursing and Midwifery associations, representatives from ministries of Education and Commissions of University Education, was held to review the draft report of the nursing harmonization study and chart the way forward for the harmonization process in EAC.

\section{Results}

The findings of the consultancy study indicated variations in nursing and midwifery education, legislation and practice across the EAC partner states. Variations were seen in cadres of nurses and midwives, curriculum, admission criteria, scope of practice, governance, and accreditation processes.

In addition, the findings indicated that nursing and midwifery education and practice in the EAC partner states faced similar challenges including; inequitable urban-rural distribution of nurses and midwives; low salaries; lack of career incentives; poor professional image; poor working conditions and environments; limited access to information and communication; shortage of equipment, medical supplies and medicines; continuous rotation changes; and inadequate referral systems.

\section{General Recommendations for Harmonization}

The EAC taskforce was established to look into education and governance issues including expected competencies at each level of curricula, scope of practice, scheme of service, and nursing and midwifery pre and postgraduate entry requirements. It was hoped that this process would standardize the quality of education and practice and lead to the establishment of an EAC regulatory body represented by all partners. Further, it was recommended that a Task Force nominated by EAC be established to look into the grading systems and equivalencies in the partner education systems in order to develop a qualification framework.

\section{Discussion}

\section{Collaborative Change: An Interdependent Model of Nursing Education}

Duma (2008) defined collaboration as "substantive interchange of human or material resources for the purpose of advancing common goals in nursing practice, education and research" (p. 9). He explained that collaboration includes sharing similar problems and similar solutions to problems. Duma further described collaboration "as a state of ART"- where A stands for five items namely; Assets, attitudes and values that each potential partner brings, Accountability to each other, Agreements to be mutual and documented, Acknowledgement of each other's contributions and Achievements monitored. $\mathbf{R}$ on the other hand stands for: Reciprocal benefits, Respect for each partner and Responsibilities well defined and agreed upon. Lastly, $\mathbf{T}$ stands for: all the essentials for a productive collaboration including; Time and timing, Tact and talent, Trust and Teething problems".

Hamner, Pattillo, Faulk, Lazenby, \& Wilder (2008) argued that with collaborative change, resources combine and form a new common identity to improve outcomes and processes. The Deans of the schools of nursing present at the end of conference meeting further agreed for the adoption of a model entitled Collaborative Change: An Interdependent Model of Nursing Education. The authors suggested that this model of cooperation would be useful to guide universities striving to collaborate and utilize nursing faculty resources effectively. They described the intersection of variables that occurred and the subsequent process of developing a unique collaboration using collaboration as a state of ART described above.

\section{Experience of Global Collaboration}

During the Global innovations in Nursing and Midwifery Education, Research andPractice Conference in Kigali Rwanda, Leshabari and Nabirye shared their experiences as members of a successful global collaboration project; the Norwegian Program for Master Studies (NOMA) project which included three universities in the South; Addis Ababa University in Ethiopia, Muhimbili University of Health and Allied Sciences in Tanzania and Makerere University in Uganda and one University in the north; Bergen University College, Norway. The aims of the project were to build capacity for the southern universities by: 
strengthening the existing MSc programs in Tanzania and Ethiopia; developing the MSc in Midwifery program in Uganda; exchanging students and teachers; developing and integrating evidence based practice and other programs in the curriculum of participating universities; and enhancing the quality of programs by exchanging external examiners.

It was noted that in this project, the "ART" as defined by Duma (2008) was fully exercised. All the components of ART were defined from the inception of the project and all members expressed their commitment to the principles.

\section{Results of the Global collaboration}

In Uganda, a master's program, MSc in Midwifery and Women's Health was established at Makerere University in August 2011. By 2014, (17) students had graduated from two cohorts. At Muhimbili University of Health and Allied Sciences (MUHAS) in Tanzania the two existing masters programs were strengthened and by 2014, 15 students graduated from critical care and 4 students graduated in mental health programs. In Ethiopia, 28 students who were supported by the project graduated from Addis Ababa University in 2014.

Nine students were fully sponsored by the NOMA project: ( 3 from each partner institution). These were staff or prospective staff at their home institutions enrolled as MSc students at partner institutions and they were expected to start the same programs in their home institutions on completion of their master studies. The three students from MUHAS who completed their MSc in Midwifery and Women's Health at Makerere University returned to MUHAS and an MSc Midwifery curriculum was established with the first cohort of students starting in 2014. Further, an advanced course in Evidence Based Practice (EBP) was organized in Norway by the Bergen University College for supervisors and teachers from all collaborating institutions. A course in EBP for MSc students has been developed and has been integrated into the curricula at all three universities in the south.

The NOMA project facilitated clinical placements for master students at world renowned institutions in South Africa (midwifery), Malawi (mental health) and Kenya (critical care \& trauma Nursing) to enhance the clinical experience of students.

\section{Lessons Learned}

There were many applicants to the NOMA project beyond the capacity of the Universities. This was an indication that nurses and midwives in the region were very interested in advancing their education. Graduates from the programs are now employed in various public and private institutions in their countries. In addition, there has been increased expertise and competence in nursing and midwifery education, research and practice and enhanced academic and administrative institutional capacity. There are also an increased number of post-graduate programs at the partner universities, attracting more applicants inside and outside of Tanzania, Uganda and Ethiopia.

The NOMA project has created a network of external examiners to enhance the quality of curricula and promote EBP. A common understanding of the importance of using evidence in nursing and midwifery care has been developed and different models for clinical learning and supervision have been explored by diversifying the clinical placements of students and creating opportunities for the development, revision and renewal of clinical teaching methods.

In order to secure sustainability, junior staff from all partner institution ( 3 from each) have received an MSc in relevant fields and thereby increased the capacity of their departments. The masters programs are institutionalized in all 3 Universities and a solid network has been created that will be of great value for future collaborations.

\section{Ongoing Collaboration in Nursing and Midwifery in East Africa}

In order to emulate and benefit from lessons learned from the NOMA project and the experiences shared during the Global innovations in Nursing and Midwifery Education, Research and Practice Conference, a meeting with EA Deans and senior faculty was held following the conference. During this meeting it was recommended that there be a regular forum for nurses and midwives to come together. It was also agreed that the international conference should be replicated and held regularly. Other recommendations from this meeting to sustain collaboration included: the development of a hub of excellence in nursing and midwifery education and research; promoting collaborative research; developing a Deans forum to plan future goals; establishing exchange visits for students, teachers and practitioners; encouraging 
inter-professional collaboration in education and practice; providing opportunities for mentorship between partner countries; and sharing technology such as e-learning.

\section{Conclusion}

Following the Global innovations in Nursing and Midwifery Education, Research and Practice Conference in Kigali Rwanda, the Dean of the School of Nursing and Midwifery at the University of Rwanda and the Deans and senior faculty from EA universities who attended the conference met to examine possible areas of collaboration between academic institutions in Tanzania, Rwanda, Uganda, Kenya and Burundi. One possibile strategy is to adapt the Collaborative Change: An Interdependent Model of Nursing Education model and integrate the experiences from the NOMA Regional Masters in Nursing. The East Africa Deans' network acted as the collaboration committee. The committee adapted the simple principles of collaborative change, including open communication, trust, and respect noted by O'Connor and Netting, 2009. The committee unanimously agreed that discussions were to be honest, open, and confidential. Communication of perceptions based on equal power led to the strengths of each organization being involved in problem solving and planned changes. Comparing the experiences with NOMA Regional Master in nursing it followed the principles of collaboration as a state of ART (Duma, 2008) that is; embracing assets, attitudes and values that each potential partner brought to the project, and acknowledged each other's contributions. Each partner was accountable to the project and to each other with documented mutual agreement. Responsibilities well defined and agreed upon and the main focus was on achievements which would be continuously monitored. It is hoped that a sustainable partnership model for advancement of Nursing and midwifery education, research and practice can be achieved.

\section{Acknowledgements}

The authors acknowledge the organizers of the Global innovations in Nursing and Midwifery Education, Research and Practice Conference which brought together nurse leaders in the EAC to discuss the development of an East African Nursing and Midwifery Deans Forum. Special thanks to Prof. Mi Ja Kim for her tireless efforts to coordinate the East Africa Nursing Deans to come together and her technical support in finalizing the manuscript.

\section{References}

Duma, S. (2008, August 2-19). Collaborative models in nursing education. Oral presentation for NEA conference. Elangeni Hotel, Durban, KZN.

East African Community (EAC). (2007). Treaty for the establishment of the East African community (amended 14th December, 2006 and 20th August, 2007). Retrieved from www.eac.int/index.php?option $=$ com docman\&task $=$ doc...gid.

East African Community (EAC). (2014). 10th ordinary meeting of the EAC Sectoral Council of Ministers of Health. Retrieved from .http://www.meac.go.tz/sites/ default/ files / documents / report $\% 20$ of $\% 20$ the $\% 20$ ministers $\% 20$ of $\% 20$ health.pdf

Hamner, J.B., Pattillo, R., Faulk, D., Lazenby, R., \& Wilder, B. (2008). Collaborative change: An interdependent model of nursing education. Southern Online Journal of Nursing Research, 8(1) Retrieved from http://www. resourcenter.net/images/snrs/files/sojnr_articles2/

Kinnaman, M. L., \& Bleich, M. R. (2004). Aligning resources to create and sustain partnerships. Journal of Professional Nursing, 20(5), 310-322.

Klopper, H.C. \& Uys, L.R. (2013). The state of nursing and nursing education in Africa: A country-by-country review. Sigma Theta Tau International, Honor Society of Nursing.

O'Connor, M.K., \& Netting, F.E. (2009). Organization practice: A guide to understanding buman service organizations (2 ${ }^{\text {nd }}$ Edition.) Wiley.

Rolince, P., Giesser, N., Greg, J., Knittel, K., Mahowald, J. F., McAloney-Madden, L., \& Schloss, R. A. (2001). A regional collaboration for educational and career mobility: The nursing education mobility action group. Nursing and Health Care Perspective, 22(12), 73-83.

World Health Assembly (WHA). (2006, May 22 -27). Resolution WHA59.23. Rapid scaling up of health workeforce production. Fifty-ninth World Health Assembly, World Health Assembly, Geneva.

World Health Assembly (WHA). (2009). Resolution 62.12. Primary health care, including health systems and strengthening. Sixty-second World Health Assembly, Geneva.

World Health Assembly (WHA). (2011). Resolution 64.7. Strengthening nursing and midwifery. Sixty-fourth World Health Assembly, Geneva.

World Health Organization (WHO). (2010). WHO code of practice on the international recruitment of health personnel. Geneva: WHO. 